\title{
Artigo
}

\section{EDUCAÇÃO AMBIENTAL EM EXTENSÃO UNIVERSITÁRIA: A operação Rondon em Conselheiro Mairinck (PR)}

\author{
ENVIRONMENTAL EDUCATION IN UNIVERSITY EXTENSION: The operation \\ Rondon in Conselheiro Mairinck (PR) \\ EDUCACIÓN AMBIENTAL EN LA EXTENSIÓN UNIVERSITARIA: La operación \\ Rondón en Conselheiro Mairinck (PR)
}

\section{Priscila Frazato da Silval, Pedro Henrique Carnevalli Fernandes"}

\begin{abstract}
'Mestranda em Ciências Biológicas pela Universidade Estadual de Londrina (UEL). Licenciada em Ciências Biológicas pela Universidade Estadual do Norte do Paraná (UENP)

"Doutor em Geografia pela Universidade Estadual de Maringá (UEM). Docente do Colegiado de Geografia da Universidade Estadual do Norte do
\end{abstract} Paraná (UENP)

\section{RESUMO}

Na sociedade atual, é fundamental o debate acerca do meio ambiente e, sobretudo, da educação ambiental. Assim, as perspectivas acadêmicas e científicas se expandem pela extensão universitária. Este artigo tem como objetivo principal compreender a educação ambiental a partir de uma atividade de extensão na Operação Rondon 2017, no município de Conselheiro Mairinck (PR). Os procedimentos metodológicos foram: levantamento bibliográfico, realização das oficinas de extensão, aplicação de questionário e análise e sistematização dos resultados. Os principais resultados mostram que mesmo muitos dos participantes assegurando que tinham algum conhecimento sobre "educação ambiental", foi possível aferir que eles adquiriram um novo conhecimento/informação com a oficina.

Palavras-chave: Educação. Meio Ambiente. Extensão. Operação Rondon.

\section{ABSTRACT}

Today, the debate about the environment and, above all, environmental education is fundamental. Thus, scientific perspectives and academic expand through university extension. This paper has as main objective to understand environmental education from an extension activity in Operation Rondon 2017, in the county of Conselheiro Mairinck (PR). The methodological procedures were bibliographic survey, conducting extension workshops, applying a questionnaire, and analyzing and systematizing the results. The main results show that even though many of the participants said that they had some knowledge about "environmental education", it was possible to verify that they acquired new knowledge/information from the workshop.

Keywords: Education. Environmental. Extension. Rondon Operation. 


\section{RESUMÉN}

En la sociedad actual, el debate sobre el medio ambiente y, sobre todo, la educación ambiental es fundamental. Así, las perspectivas académicas y científicas se expanden a través de la extensión universitaria. Este artículo tiene como objetivo principal comprender la educación ambiental a partir de una actividad de extensión en la Operación Rondón 2017, en el municipio de Conselheiro Mairinck (PR). Los procedimientos metodológicos fueron: levantamiento bibliográfico, realización de talleres de extensión, aplicación de cuestionario y análisis y sistematización de resultados. Los principales resultados muestran que a pesar de que muchos de los participantes dijeron tener algún conocimiento sobre "educación ambiental", fue posible verificar que adquirieron nuevos conocimientos/información del taller.

Palabras clave: Educación. Medio ambiente. Extensión. Operación Rondon.

\section{INTRODUÇÃO}

Na sociedade contemporânea, o papel da Universidade (e, portanto, do Ensino Superior) precisa ir além do ensino. A extensão universitária deve ocorrer efetivamente, de modo que a universidade ultrapasse as barreiras do seu espaço físico. Nesse sentido, segundo Nunes e Silva (2011, p. 120), a extensão universitária é "uma forma de interação (...) entre a universidade e a comunidade".

Logo, só existe extensão quando ocorre uma inter-relação entre a Universidade, por meio dos professores e acadêmicos, e a comunidade local. Essa conexão ocorre por meio de um processo educativo, cultural e científico que articula o ensino e a pesquisa (NUNES; SILVA, 2011), de modo que se ensina e, ao mesmo tempo, se aprende.

Este artigo tem como objetivo principal compreender a educação ambiental a partir de uma atividade de extensão na Operação Rondon 2017, no município de Conselheiro Mairinck (PR). Os objetivos específicos são: (i) apresentar noções teóricas de educação ambiental; (ii) demonstrar os resultados das oficinas aplicadas nos moradores locais; e (iii) refletir acerca da extensão universitária em consonância com a realidade da população local.

O município de Conselheiro Mairinck está localizado na Mesorregião Norte Pioneiro do Paraná (IBGE, 2010). A Figura 1 apresenta um mapa de localização do município, que tem 3.636 habitantes, sendo $70 \%$ de população urbana (IBGE, 2010), uma área de 204,7 quilômetros quadrados, gerando uma densidade demográfica de 
18 habitantes por quilômetro quadrado (IBGE, 2010), e está a quase 350 quilômetros da capital do Paraná, Curitiba (IBGE, 2010). A Figura 2 mostra uma imagem aérea da cidade de Conselheiro Mairinck, em 2019.

O município teve origem do Patrimônio da Maria Souza, situado às margens de um pequeno ribeirão, sendo que esse nome é homenagem a uma pioneira que ocupou as terras localizadas nessa área e construiu um primeiro rancho (CONSELHEIRO MAIRINCK, 2017).

Figura 1: Conselheiro Mairinck (PR). Localização, 2020

\section{Norte Pioneiro do Paraná. Conselheiro Mairinck, 2020}

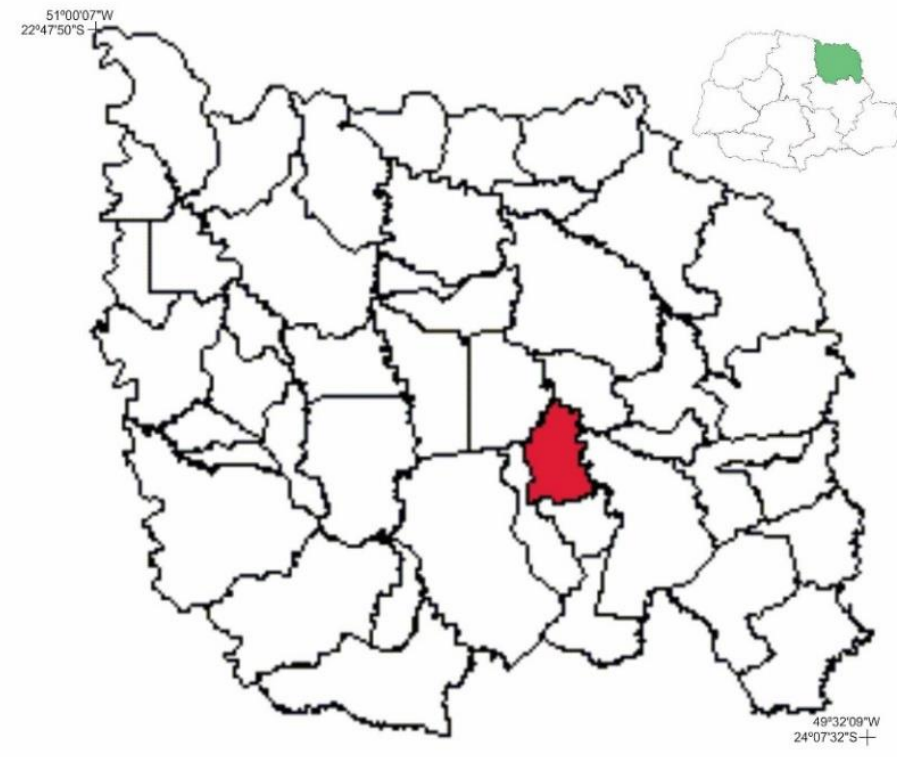

Norte Pioneiro

Conselheiro

Mairinck

Base Cartográfica: Instituto Brasileiro de Geografia e Estatística (IBGE).

Elaboração: Prof. Dr. Pedro Henrique Carnevalli Fernandes (18/07/2020).

Fonte: Adaptado de IBGE (2010) 
Figura 2: Conselheiro Mairinck (PR), 2019

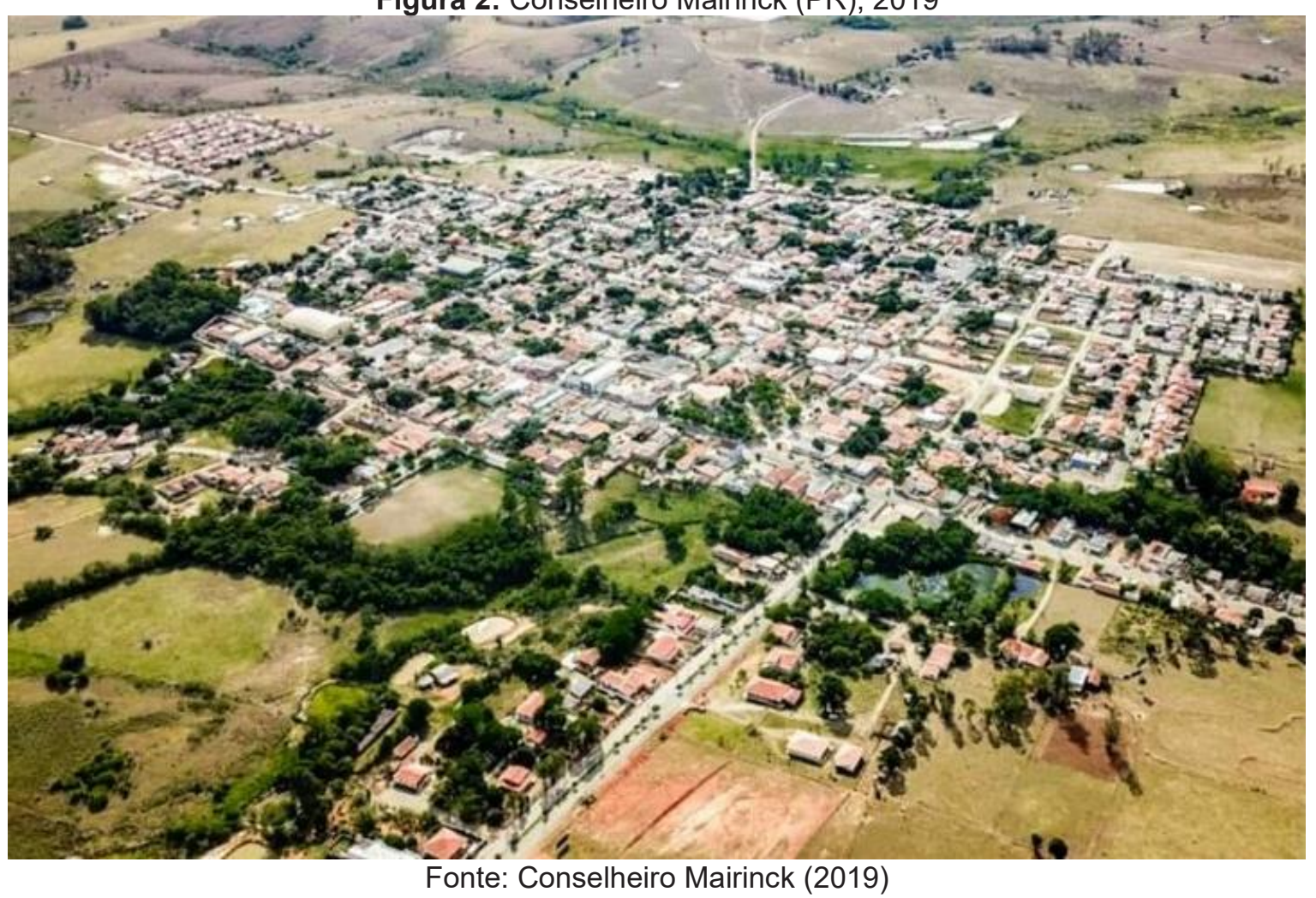

Em 1951, o Patrimônio da Maria Souza transformou-se em Distrito Judiciário, pertencente ao município e comarca de Tomazina, passando a denominar-se "Conselheiro Mairinck" (CONSELHEIRO MAIRINCK, 2017). Em 1954, o distrito passou para o município de Japira e, em 1960, o distrito de Conselheiro Mairinck foi elevado à categoria de município (CONSELHEIRO MAIRINCK, 2017). O nome da cidade é uma homenagem a um pioneiro (CONSELHEIRO MAIRINCK, 2017).

O artigo está estruturado, além da introdução e das considerações finais, em quatro partes: na primeira, discorre-se acerca da metodologia e dos procedimentos metodológicos; na segunda parte, destaca-se a essência da Operação Rondon, realizada em 2017, no Norte Pioneiro do Estado do Paraná; a terceira apresenta a base teórica da educação ambiental; e, por fim, a quarta parte transita pelos resultados empíricos das oficinas sobre educação ambiental aplicadas em Conselheiro Mairinck.

\section{METODOLOGIA}


Os procedimentos metodológicos para a realização deste artigo foram: levantamento bibliográfico acerca da extensão universitária e da educação ambiental; descrição e análise da preparação do projeto de extensão; descrição, análise reflexiva dos resultados e registro fotográfico da realização de oficinas de extensão durante a Operação Rondon em Conselheiro Mairinck (PR); e, finalmente, sistematização dos resultados na elaboração da redação final deste artigo.

As oficinas relacionadas à temática do "meio ambiente" foram construídas com a proposta de serem aplicadas em pessoas de diferentes idades da comunidade local. Assim, foram escolhidos três temas principais: reciclagem, educação ambiental e horta. Neste artigo, aborda-se os resultados das oficinas sobre Educação Ambiental.

A oficina foi apresentada em forma de palestra expositiva-dialogada, onde a interação e a participação dos ouvintes foram importantes para o desenvolvimento da oficina. A oficina contou com o auxílio de um retroprojetor e teve duração de sessenta minutos, incluindo um momento de dúvidas e de debates no final.

As oficinas tiveram um alcance total de 31 pessoas (quase $1 \%$ da população total do município), sendo realizadas no Serviço de Convivência e Fortalecimento de Vínculo (Peti) e na Escola Estadual Dona Macaria. Para os alunos do Peti, a oficina desenvolveu uma atividade prática de reciclagem, com rolos de papel higiênico, na qual eles confeccionavam e personalizavam corujas, e uma visita de campo a uma nascente que fica próxima da cidade, onde eles puderam ver e aprender sobre a importância da conservação desse tipo de ambiente.

Um questionário foi aplicado antes e depois da oficina em cada um dos participantes como instrumento de investigação. É importante destacar que os questionários não foram identificados com os nomes dos participantes de modo que eles pudessem responder com o máximo de sinceridade. O questionário aplicado antes de começar a oficina era composto por duas perguntas e tinha como objetivo compreender o conhecimento prévio dos participantes. As perguntas foram:

01) Como você classifica o seu conhecimento sobre Educação Ambiental?
( ) Muito elevado
( ) Razoável
( ) Não tem conhecimento

02) Você contribui para o meio ambiente?

( ) Não ( ) Sim, de que forma? 
Ao final de cada oficina também foi pedido para que os participantes respondessem um questionário composto por duas perguntas fechadas e uma aberta, sendo que nesta última eles deveriam escreveram um relato breve sobre o que haviam aprendido ou acrescentado aos seus conhecimentos durante a oficina. As perguntas do questionário aplicado no final da oficina foram:

01) A oficina acrescentou algo no seu conhecimento sobre Educação Ambiental?

\section{( ) $\operatorname{Sim}($ ) Não}

02) Você pretende passar esses novos conhecimentos para outras pessoas? ( ) Sim ( ) Não

03) Faça um relato sobre o que você achou da oficina e o que ela acrescentou em seus conhecimentos sobre o assunto.

Para analisar as respostas da pergunta aberta, os participantes foram codificados de acordo com o grupo em que a oficina foi ministrada: comunidade escolar de "P1 - C.E." a "P21 - C.E." e participantes da oficina no Peti de "P1 - Peti" a "P10 - Peti".

\section{A OPERAÇÃO RONDON 2017}

A Operação Rondon é um projeto de extensão criado pela Universidade Estadual de Ponta Grossa (UEPG) em 2015. O objetivo desse projeto é "possibilitar a relação entre a Universidade e a Sociedade com ações transformadoras capazes de promover soluções aos problemas locais e regionais” (UEPG, 2017, p. 3).

A Operação Rondon viabiliza o trabalho voluntário de professores, agentes e estudantes universitários no município, contribuindo para o seu desenvolvimento. Ao mesmo tempo, possibilita aos universitários conhecerem de perto a realidade brasileira e sentirem os anseios da população (UEPG, 2017).

Em 2015, a Operação Rondon foi realizada em seis municípios da região dos Campos Gerais do Paraná; no ano seguinte, ocorreu em quatro municípios da mesma região; e, finalmente, em 2017, a Operação Rondon deixou os Campos paranaenses 
e foi realizada em dez municípios do Norte Pioneiro do Estado do Paraná (UEPG, 2017).

Na Operação Rondon de 2017, realizada entre julho e agosto, o projeto foi coordenado pela UEPG em parceria com a Universidade Estadual do Norte do Paraná (Uenp) e teve como foco contribuir para a formação universitária como cidadão e para o desenvolvimento sustentável de municípios, sobretudo aqueles demograficamente pequenos e com indicadores sociais problemáticos.

Embora a Operação Rondon seja recém-criada, ela se assemelha ao Projeto Rondon, do Governo Federal, por meio do Ministério da Defesa, que possui amplo reconhecimento e efetividade nacional. Nesse sentido, a extensão rondonista se configura como uma poderosa ferramenta de transformação, priorizando, sobretudo, a formação de multiplicadores na comunidade.

Essa justificativa, também, caminha pela percepção de que as ações acabam ganhando efeitos duradouros na sociedade local e valores humanitários nos universitários participantes.

\section{DEBATE TEÓRICO ACERCA DA EDUCAÇÃO AMBIENTAL}

Muitos ainda acreditam que os problemas ambientais de escassez de recursos se dão pelo aumento exacerbado da população mundial, sendo essa uma ideia que teve origem e repercussão no início dos anos 1960 na Europa (REIGOTA, 2017). Essa perspectiva ocorreu quase cem anos depois da Revolução Industrial, onde as consequências no meio ambiente começaram a ser percebidas (JUNIOR, 2015). Contrapondo essa ideia, pesquisadores de países não industrializados demonstraram que o problema dos recursos ambientais não estava no número de pessoas no mundo, mas na concentração das riquezas e no consumo pelos países industrializados, provocadas pelo modelo capitalista (REIGOTA, 2017).

Em 1972, a Organização das Nações Unidas (ONU) realizou a primeira Conferência Mundial de Meio Ambiente Humano em Estocolmo, na Suécia, e a partir de então se convencionou chamar as práticas educativas relacionadas às questões ambientais de Educação Ambiental, surgindo como uma resposta para enfrentar os 
problemas de ordem ambiental (REIGOTA, 2017). Desde que se evidenciou esse termo, diversas classificações e denominações explicitaram as concepções que preencheram de sentido as práticas e reflexões pedagógicas ligadas à questão ambiental (LAYRARGUES, 2004).

Uma resolução importante daquela primeira conferência foi a que se deveria educar o cidadão e a cidadã para a solução dos problemas ambientais (REIGOTA, 2017). A década de 1970 se destacou pelas primeiras ações conjuntas de entidades e movimentos ambientais, que buscavam o controle das questões do meio ambiente (DE MOURA CARVALHO, 2017).

Nessa mesma época, no Brasil, aconteciam muitos episódios contrários à conservação do meio ambiente, tais como a instalação de empresas multinacionais poluidoras, que na maioria das vezes eram impedidas de operar em seus próprios países, sendo que o país ainda defendia o lema de que "a poluição é o preço que se paga pelo progresso" (REIGOTA, 2017). Já nos anos 1980 e 1990 houve progressivo diálogo e aproximação, com mútua influência, entre as lutas ecológicas e os movimentos sociais urbanos no Brasil (DE MOURA CARVALHO, 2017).

Em 1983, a ONU convidou a médica e mestre em saúde pública Gro Harlem Brundtland para administrar a Comissão Mundial sobre o Meio Ambiente e Desenvolvimento (BRUNDTLAND, 1991). A Comissão Brundtland ficou reconhecida quando publicaram um relatório (que depois de tornou um livro) chamado "Nosso Futuro Comum", que trouxe o conceito de desenvolvimento sustentável (BRUNDTLAND, 1991). O Relatório de Brundtland também enfatizou a importância da Educação Ambiental para a solução dos problemas ambientais (REIGOTA, 2017).

Em 1990, foi possível presenciar no mundo uma quantidade enorme de acidentes e de diretrizes políticas completamente antiecológicas, inclusive no Brasil o desmatamento atingiu índices alarmantes (REIGOTA, 2017). Apenas em 1992 aconteceu uma Conferência Mundial das Nações Unidas sobre o Meio Ambiente e o Desenvolvimento, no Rio de Janeiro, a chamada "Rio-92", referente às questões ambientais e ao desenvolvimento sustentável, com o objetivo de discutir e construir um documento para descrever conceito de sociedade sustentável (CORDANI, MARCOVITCH, SALATI, 1997). 
Essa foi a primeira conferência das Nações Unidas em que cidadãos do mundo todo puderam participar (CORDANI, MARCOVITCH, SALATI, 1997). Foi nesse momento que a Educação Ambiental deixou de ser conhecida apenas por pequenos grupos militantes e a necessidade de formar cidadãos para atuar diante dos problemas e desafios ambientais se consolidou (LIMA, 2009). Assim, a Educação Ambiental ganhou uma força significativa no Brasil.

No início, a educação ambiental era relacionada apenas à conservação de vegetais e animais, sendo isso na verdade a ecologia biológica, tirando o peso de se preocupar com os problemas sociais e políticos que de fato provocavam essa situação de desaparecimento de espécies, embora essas questões biológicas sejam de extrema importância e devem receber muita atenção (REIGOTA, 2017).

Essa visão "naturalizada" tende a mostrar a natureza como algo à parte, existindo pacificada, equilibrada e vivendo como autônoma e independente da interação com o mundo cultural humano, como se o ser humano não fizesse parte dela, e tudo que envolve a ação do ser humano na natureza aparecesse como uma problemática ocasionando apenas prejuízos (DE MOURA CARVALHO, 2017). A consequência de uma visão predominantemente naturalista-conservacionista é a redução do meio ambiente a apenas uma de suas dimensões, simplificada e reduzida, desprezando a riqueza da permanente interação entre a natureza e a cultura humana (GUIMARÃES, LAYRARGUES, 2004).

Essa visão dicotômica de mundo sustenta uma relação desintegrada entre a sociedade e a natureza e essa é uma percepção que tem dificuldade de pensar em conjunto, acaba focado só na parte e privilegiando uma dessas partes, o ser humano sobre as demais, estabelecendo uma diferença hierarquizada que constrói uma ideia de dominação (GUIMARÃES, LAYRARGUES, 2004). No entanto, só por meio da natureza que o ser humano reencontra parte de sua própria identidade humana, de identidade de ser vivo entre os demais seres vivos (SAUVÉ, 2005).

A educação ambiental é política. Quando se pensa a educação ambiental como uma educação ambiental política é possível ampliar o seu alcance e tirar da dominação de apenas uma parcela da população, que na maioria das vezes impede a participação livre, consciente e democrática de todos (REIGOTA, 2017). Os 
cidadãos devem ser colocados como atuantes de forma ativa e livre, ajudando na busca de soluções e alternativas que permitam a convivência digna e voltada para o bem comum (REIGOTA, 2017). Dessa forma, ela deve ser um ato político voltado para a transformação social.

A participação e a mudança no comportamento são elementos importantes na educação ambiental (REIGOTA, 2017). Assim, a educação ambiental deve primeiramente focar em "por que" fazer e depois enfatizar o "como" fazer algo (REIGOTA, 2017). Um ser humano autônomo capaz de refletir sua própria aprendizagem é o princípio de toda mudança, logo, a educação é relação e se dá no processo e não simplesmente no sucesso da mudança comportamental de um indivíduo (GUIMARÃES, LAYRARGUES, 2004).

A Educação Ambiental Crítica aparece como uma importante ferramenta nos problemas de ordem ambiental, se interessando pela investigação crítica das realidades do meio em que se vive, ou seja, de tomar consciência de que os problemas ambientais estão essencialmente associados a questões socioambientais (SAUVÉ, 2005). Essa corrente busca entender como se entrelaçam os mais diversos fatores que compõem os conhecimentos e a realidade e parte do princípio de que o conhecimento, a cultura e a história são produtos humanos e que se transformam permanentemente a partir da ação humana sobre o mundo (GUIMARÃES, LAYRARGUES, 2004).

A Educação Ambiental Crítica tende a rejeitar o antropocentrismo e a consequente subordinação da natureza, se propõe a desvendar os problemas presentes para a compreensão complexa do real, para que os atores sociais venham interferir nessa realidade (LIMA, 2009). E não atuando apenas passivamente, acreditando que só transmitir o conhecimento correto fará com que o indivíduo compreenda a problemática ambiental e que isso irá transformar seu comportamento e a sociedade (GUIMARÃES, LAYRARGUES, 2004). Em outras palavras, as ações devem superar a mera transmissão de conhecimentos ecologicamente corretos.

Apenas mostrando os determinantes causais da crise que será possível atuar e enfrentar o problema na sua causa e consciência, nesse sentido, a Educação Ambiental Crítica é emancipatória e transformadora, conhece os fatores e 
determinantes históricos, os contextos de cada formação socioeconômica das relações sociais na natureza, e constrói uma práxis que gera a percepção da causa dos problemas de ordem ambiental (DE MOURA CARVALHO, 2017). Esse não é um exercício individual, mas em movimentos coletivos conjuntos de transformação da realidade socioambiental (GUIMARÃES, LAYRARGUES, 2004).

O ser humano já não se vê mais como um elemento da natureza, mas um ser a parte, apenas um observador e/ou explorador dela, por isso, é preciso reconstruir o sentimento de pertencer à natureza e ao fluxo de vida (SAUVÉ, 2005). O surgimento da questão ambiental como um problema que afeta o destino da humanidade tem mobilizado governos e sociedade civil, iniciando uma busca por estratégias que pudessem auxiliar na resolução ou pelo menos na mitigação dos problemas ambientais (DE MOURA CARVALHO, 2017).

Nesse contexto, surge a educação ambiental como um dos mais importantes meios, uma das formas mais significativa de tentar modificar esse cenário. Em 27 de abril de1999, foi sancionada a Lei Federal № 9.795 (regulamentada em 2002), que institui a "Política Nacional de Educação Ambiental" (BRASIL, 1999). Em seu artigo primeiro há definição de Educação Ambiental: "Entendem-se por educação ambiental os processos por meio dos quais o indivíduo e a coletividade constroem valores sociais, conhecimentos, habilidades, atitudes e competências voltadas para a conservação do meio ambiente, bem de uso comum do povo, essencial à sadia qualidade de vida e sua sustentabilidade" (BRASIL, 1999, s. p.). No artigo segundo, a lei estabelece que todos têm direito à educação ambiental: "componente essencial e permanente da educação nacional, devendo estar presente em todos os níveis e modalidades do processo educativo, em caráter formal e não formal" (BRASIL, 1999, s. p.).

Nas últimas décadas, vem sendo instituído um conjunto de práticas sociais voltadas para o meio ambiente, tanto no âmbito das legislações e dos programas de governo quanto nas diversas iniciativas em grupos, associações e de movimentos ecológicos (DE MOURA CARVALHO, 2017).

Portanto, na educação formal, o processo educativo não se basta apenas dentro dos muros de uma escola, e considerando a própria gravidade da crise 
ambiental para a manutenção da vida no planeta e a emergência do enfrentamento dela, não há como pensar em um público privilegiado para a Educação Ambiental (GUIMARÃES, LAYRARGUES, 2004). Sendo assim, o público da Educação Ambiental é constituído por seus atores individuais e coletivos, em todas as faixas etárias (GUIMARÃES, LAYRARGUES, 2004).

Uma das características mais importantes do movimento ambientalista é a sua diversidade, onde todas as pessoas podem fazer parte e ela deve estar presente em todos os espaços que educam o cidadão e a cidadã, assim ela pode ser realizada em todos os espaços, escola, nos parques e reservas ecológicas, nas associações de bairro, nos sindicatos, nas universidades, nos meios de comunicação de massa, entre outros (JACOBI, 2003).

A educação ambiental provoca uma educação para a conservação, para o consumo responsável e para a solidariedade na repartição equitativa dentro de cada sociedade, entre as sociedades atuais e as futuras (SAUVÉ, 2005). É urgente a mudança para uma forma de desenvolvimento que garanta a sobrevivência das futuras gerações.

\section{A EDUCAÇÃO AMBIENTAL POR MEIO DAS OFICINAS DE EXTENSÃO UNIVERSITÁRIA}

A oficina começou com uma apresentação de slides mostrando imagens "desagradáveis", ou seja, de paisagens com o meio ambiente destruído, como queimadas e poluição, intercaladas com imagens "agradáveis", ou seja, com belas paisagens de ambientes conservados e limpos.

Ao longo da apresentação das imagens, os participantes eram instigados a avaliarem a condição do meio ambiente em cada uma das figuras. $O$ intuito final dessa etapa foi começar a conscientização de que a cada dia que passa as paisagens "desagradáveis" estão se tornando mais comum. As paisagens "agradáveis", que antes eram mais frequentes e em maior quantidade, vão sendo substituídas por paisagens com poluição, queimada, desmatamento, entre outros. 
Após as imagens, o conteúdo da oficina seguiu com tópicos mais teóricos relacionados ao assunto, sempre associados com imagens para ajudar na contextualização do tema, vindo de encontro com um aprendizado de maneira mais lúdica e prazerosa.

Alguns dos tópicos abordados destacavam as medidas para cuidar do meio ambiente, como: (i) maneiras de economizar água; (ii) reciclagem - Lei n 12.305/2010 - Política Nacional de Resíduos Sólidos (PNRS); (iii) economia de energia; (iv) evitar o consumo exagerado; (v) Educação e preservação, os benefícios de se cuidar do meio ambiente.

A Figura 3 apresenta fotografias da aplicação da oficina de educação ambiental para os alunos do Peti de Conselheiro Mairinck. A Figura 4 demonstra a aplicação da oficina para professores da rede pública estadual de ensino.

Figura 3: Conselheiro Mairinck (PR). Aplicação da oficina de educação ambiental para os alunos do

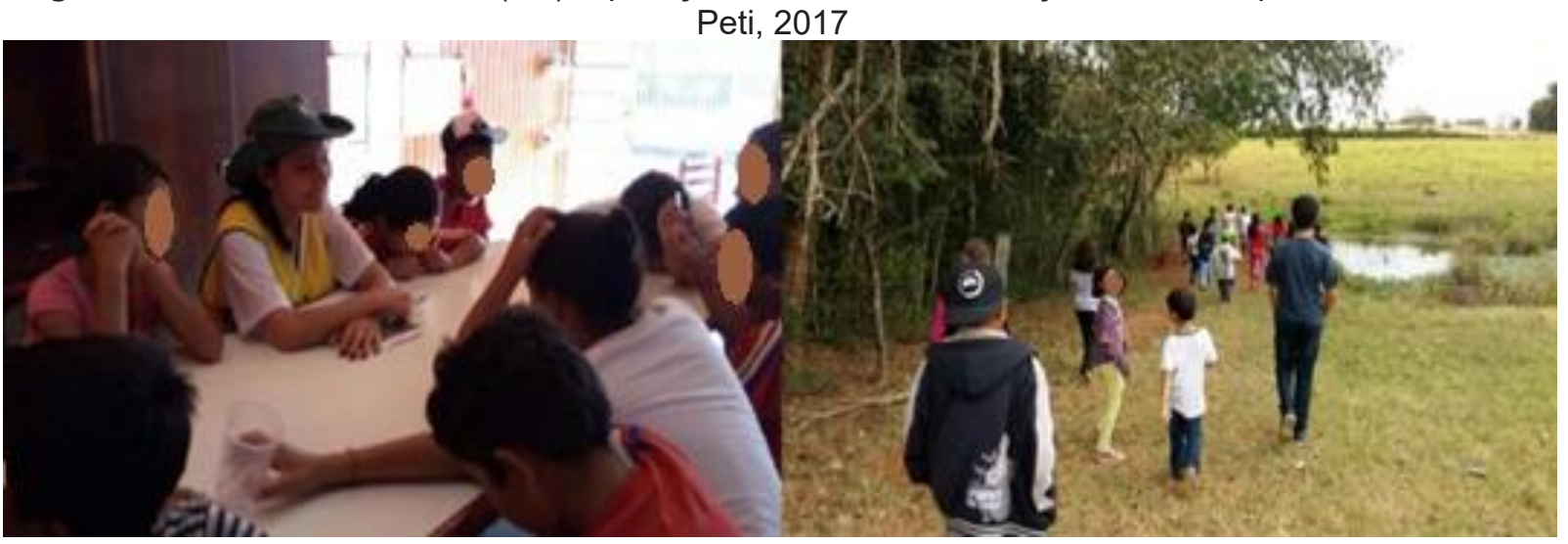

Fonte: Acervo dos autores 
Figura 4: Conselheiro Mairinck (PR). Aplicação da oficina de educação ambiental para professores da rede pública estadual, 2017

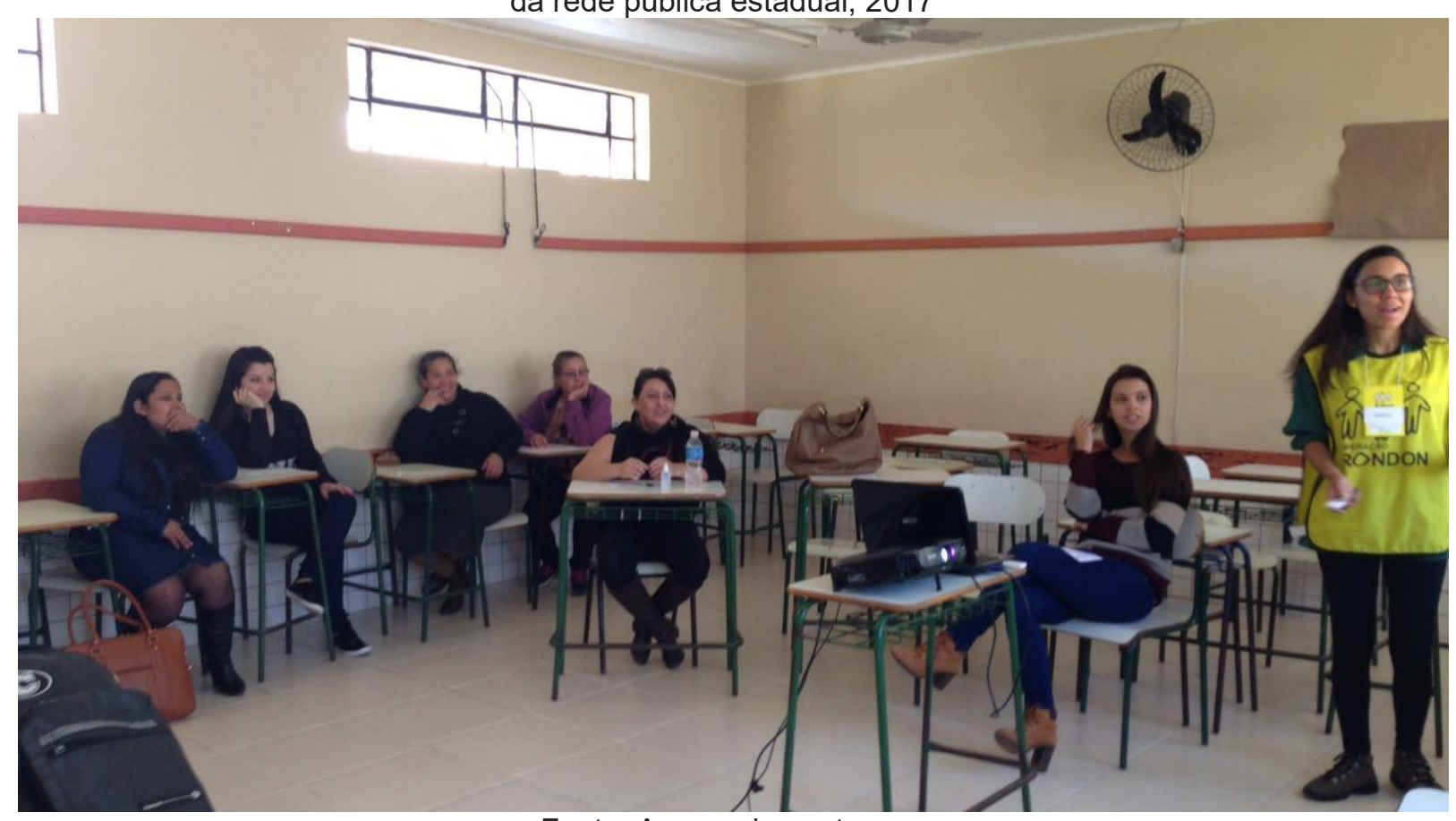

Fonte: Acervo dos autores

Inicia-se com a análise dos resultados do questionário aplicado antes do início da oficina de educação ambiental. A Figura 5 apresenta a autoclassificação realizada pelo respondente-participante quanto ao seu conhecimento sobre o tema da educação ambiental em Conselheiro Mairinck (PR). 
Figura 5: Conselheiro Mairinck (PR). Percepção dos respondentes antes da oficina Como você classifica o seu conhecimento sobre Educação Ambiental?

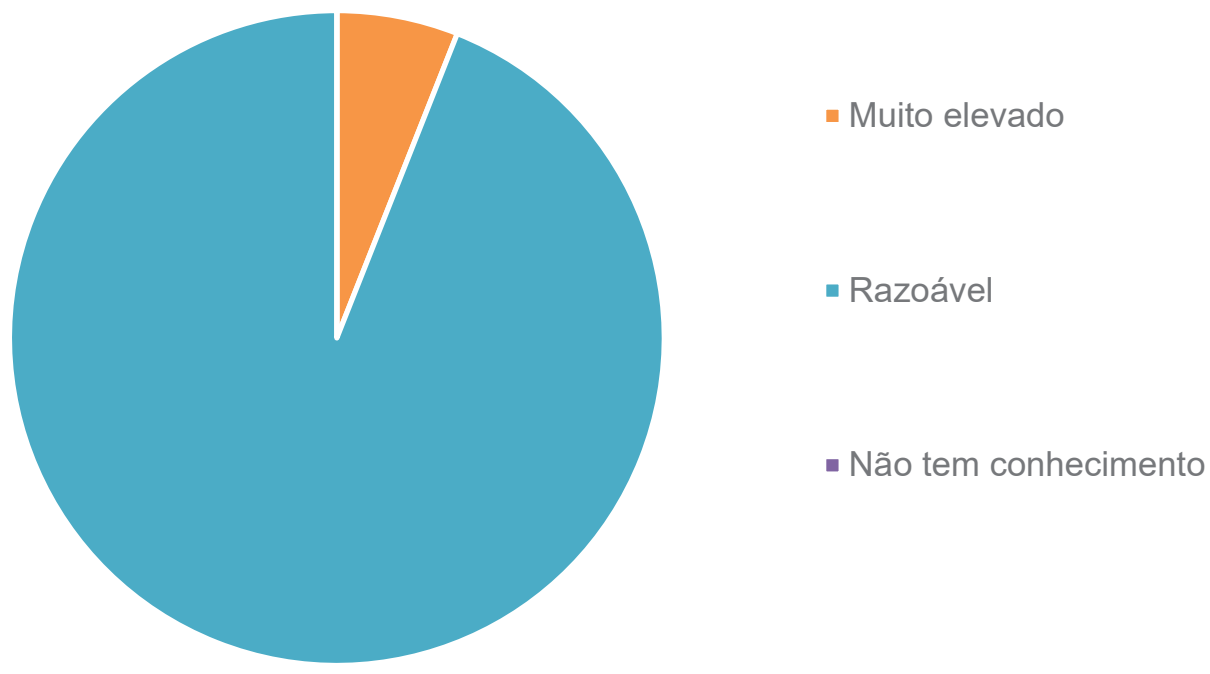

Fonte: Trabalho empírico (2017)

Os dados mostram que $94 \%$ dos respondentes-participantes das oficinas classificaram o seu conhecimento sobre educação ambiental como "razoável". Isso revela que como demonstra a literatura, a Educação Ambiental deixou, após a década de 1990, de ser conhecida apenas por pequenos grupos de interessados e se disseminou para a sociedade em geral (LIMA, 2009).

Então, a educação ambiental conseguiu se consolidar no Brasil e se tornar um tema de debate. Apesar disso, entende-se que é preciso qualificar essa educação. Os demais $6 \%$ dos respondentes-participantes classificaram o seu conhecimento como "muito elevado"; ninguém respondeu que "não tem conhecimento" sobre o assunto, o que é um dado importante para o avanço que se espera sobre a educação ambiental.

Quanto à segunda questão do questionário precursor da oficina, todos os respondentes-participantes (100\%) alegaram que contribuem com o meio ambiente. Isso é muito relevante, pois como Reigota (2007) a participação e a mudança no comportamento são elementos importantes na educação ambiental, sobretudo por meio de um ser humano autônomo e capaz de refletir sua própria aprendizagem 
(GUIMARÃES, LAYRARGUES, 2004). O Quadro 1 apresenta algumas das formas citadas por esses respondentes-participantes de Conselheiro Mairinck (PR).

É possível constatar que a maioria dos respondentes indicou ações de preservação do meio ambiente, como economizando água, separando e dando destino adequado ao lixo e praticando limpezas no meio ambiente. É importante destacar que um respondente enfatizou a ideia de "conscientização".

Quadro 1. Conselheiro Mairinck (PR). "Você contribui para o meio ambiente? Se sim, de que forma?"

\begin{tabular}{|l|l|}
\hline P2 - C.E & Economizando água, separando lixo... \\
\hline P4 - C.E & $\begin{array}{l}\text { Separando e organizando o lixo; e outras coisas como economizando a } \\
\text { água }\end{array}$ \\
\hline P6 - C.E & Não poluindo, preservando e conscientizando os alunos \\
\hline P16 - C.E & $\begin{array}{l}\text { Além de práticas na escola com alunos, cuidados com água, lixo, entre } \\
\text { outros }\end{array}$ \\
\hline P1 - Peti & Não jogando lixo no chão \\
\hline P3 - Peti & Todo o domingo eu meu tio saímos atrás de litros para não cair na mata \\
\hline P8 - Peti & Jogando lixo no lixo e não desperdiçar comida \\
\hline
\end{tabular}

Fonte: Trabalho empírico (2017)

Após a aplicação das oficinas, um novo questionário foi aplicado nos participantes. Assim, a Figura 6 e a Figura 7 apresentam os resultados acerca da percepção dos respondentes após a realização das oficinas em Conselheiro Mairinck $(P R)$, quanto aos conhecimentos sobre educação ambiental adquiridos e quanto à ideia de transmitir esses conhecimentos, se tornando multiplicadores.

Na primeira pergunta do questionário aplicado após a realização da oficina, os dados mostram que todos os participantes-respondentes (100\%) afirmaram que a oficia acrescentou algo para o seu conhecimento sobre a educação ambiental. Isso é um dado muito interessante, pois indica que até as pessoas que afirmaram anteriormente ter um conhecimento elevado sobre o assunto, declararam ter aprendido algo novo. Na segunda pergunta, que é de extrema importância, os resultados mostram que todos os participantes-respondentes (100\%) indicaram que 
irão repassar os conhecimentos adquiridos nas oficinas de educação ambiental para outras pessoas das pequenas cidades, o que certamente amplia de alguma forma a conscientização sobre cuidados com o meio ambiente e torna esses participantes da oficina em multiplicadores, o que é uma das essências da extensão universitária.

Figura 6: Conselheiro Mairinck (PR). Percepção dos respondes acerca de novos conhecimentos

Você pretende passar esses novos conhecimentos?

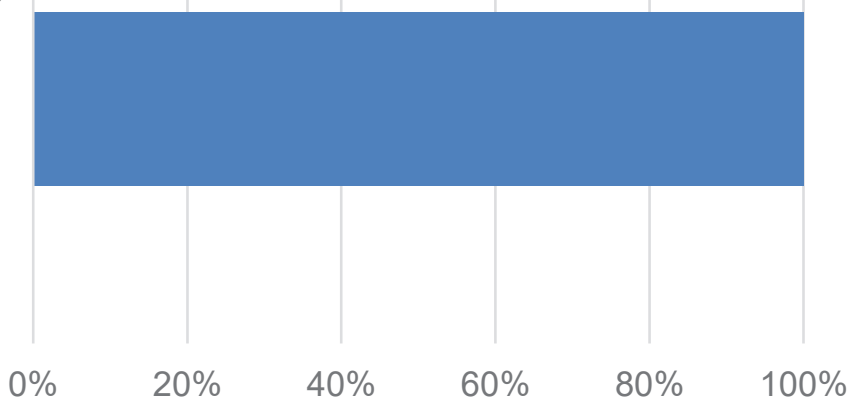

- Não $\quad$ Sim

Fonte: Trabalho empírico (2017) 
Figura 7: Conselheiro Mairinck (PR). Percepção dos respondes acerca de transmissão dos novos conhecimentos

Você pretende passar esses novos conhecimentos?

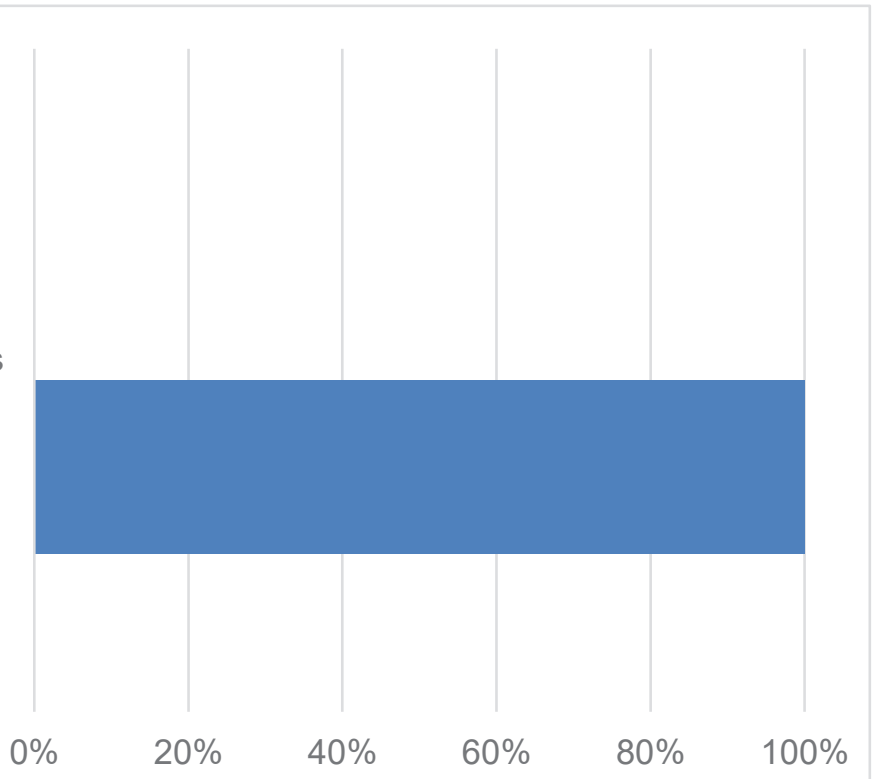

- Não $\quad$ Sim

Fonte: Trabalho empírico (2017)

Finalmente, quanto à terceira pergunta, os respondentes-pesquisadores foram convidados a fazerem um relato sobre o que acharam da oficina e o que ela acrescentou em seus conhecimentos sobre a educação ambiental. Para analisar essas respostas, os questionários também foram codificados. O Quadro 2 apresenta algumas das formas citadas por esses respondentes-participantes de Conselheiro Mairinck (PR) após a realização das oficinas. 
Quadro 2: Conselheiro Mairinck (PR). Relatos sobre a aplicação da oficina

\begin{tabular}{|l|l|}
\hline $\begin{array}{l}\text { Faça um relato sobre o que você achou da oficina e o que ela acrescentou em seus } \\
\text { conhecimentos sobre o assunto }\end{array}$ \\
\hline P1 - C.E & $\begin{array}{l}\text { Oficina muito boa, nos ensinou um pouco mais, mais informações para passarmos aos } \\
\text { nossos alunos }\end{array}$ \\
\hline P2 - C.E & $\begin{array}{l}\text { A oficina foi muito interessante, aprendemos coisas diferentes que vamos pôr em } \\
\text { prática e ensinar aos nossos alunos }\end{array}$ \\
\hline P8 - C.E & $\begin{array}{l}\text { Poderia ser abordado questões sobre sistemas de tratamento de esgoto para casa } \\
\text { que não tenham coleta de esgoto. }\end{array}$ \\
\hline P13 - C.E & $\begin{array}{l}\text { Este projeto oportunizou e esclareceu assuntos necessários e importante para nossa } \\
\text { vida e do nosso planeta }\end{array}$ \\
\hline P1 - Peti & $\begin{array}{l}\text { Essa oficina foi muito legal a gente aprendeu muita coisa, como não jogar lixo no rio e } \\
\text { não matar árvores. }\end{array}$ \\
\hline P3 - Peti & $\begin{array}{l}\text { Eu aprendi a importância da natureza, como reciclar, não jogar lixo na rua e a separar } \\
\text { lixo }\end{array}$ \\
\hline P5 - Peti & $\begin{array}{l}\text { Essa oficina foi boa eu aprendi que para preservar o meio ambiente: não demorar no } \\
\text { banho, não jogar papel na rua e não deixar luz ligada }\end{array}$ \\
\hline P8 - Peti & Eles falaram sobre separar lixo, não gastar energia e também cuidar do meio ambiente \\
\hline
\end{tabular}

Fonte: Trabalho empírico (2017)

A terceira pergunta aberta do questionário apresenta comentários dos participantes, tanto da forma como ela foi transmitida como os conteúdos que foram abordados. Também tiveram comentários com críticas construtivas, da qual os participantes citaram outros temas sobre educação ambiental que poderiam ser abordados. Assim, espera-se ter contribuído com o movimento ambientalista por meio da diversidade, como apontou Jacobi (2003). A educação ambiental provoca uma educação para a conservação, como destacou Sauvé (2005), e é preciso conscientização e ação das pessoas.

\section{CONSIDERAÇÕES FINAIS}

A construção de cidadãos críticos e ambientalmente conscientes não é uma tarefa fácil, muito menos rápida, mas é um trabalho para ser estruturado dia a dia. Trazer a memória conhecimentos já aprendidos pelas pessoas e a adição de novas percepções, consolidam e fortalecem a ação correta a ser tomada diante da atuação do ser humano na natureza. Não apenas uma falsa ideia ilusória naturalista que segrega do todo, mas, pelo contrário, é um sentimento de pertencimento ao meio 
ambiente, tendo a convicção de que a educação ambiental é política (REIGOTA, 2017).

Ao comparar os questionários dos participantes das oficinas de educação ambiental foi possível notar que mesmo a maioria ter afirmado antes dela que eles tinham algum conhecimento do assunto, no final de cada oficina os relatos mostraram que eles adquiriram um novo conhecimento/informação do assunto. Dessa forma, as oficinas de educação ambiental aplicadas aos cidadãos de Conselheiro Mairinck apontam ter sido de extrema relevância, cumprindo com um dos principais objetivos da Operação Rondon, atuando como uma poderosa ferramenta de transformação, gerando multiplicadores na comunidade.

Temas como esses são relevantes e devem ser motivados. Vive-se em uma época carregada de informações, muitas delas trazem consigo interesses particulares. Logo, nada melhor do que filtrar e valorizar as informações corretas que são trabalhadas dentro das universidades e onde os professores e acadêmicos têm contato todos os dias. Ajudando a comunidade a ver coerência no meio de tanta informação, bem como saber suas fontes e implicações na vida real. Por outro lado, a extensão universitária é uma troca de conhecimento, sobretudo o popular de comunidades, o que certamente enriquece professores e acadêmicos universitários.

Isso reforça a importância de ações como o projeto de extensão Operação Rondon, no engajamento de discussões como a de educação ambiental. A todo momento durante a realização da operação no município de Conselheiro Mairinck foi possível notar a troca de experiências entre professores, acadêmicos e comunidade local, essa prática é enriquecedora e gera frutos permanentes. Essas ações que geram a mudança de comportamento hoje, pode garantir a sobrevivência das gerações futuras bem como uma melhoria de vida para todos os seres das atuais gerações.

\section{REFERÊNCIAS}

BRASIL, Comissão de Políticas de Desenvolvimento. Lei n. 9.795, de 27 de abril de 1999: Dispõe sobre a educação ambiental, institui a Política Nacional de Educação Ambiental e dá outras providências. Diário Oficial da União, Brasília, v. 28, 1999. 
BRUNDTLAND, Gro Harlem et al. Nosso futuro comum. Rio de Janeiro: FGV, p. 172-182, 1991.

CONSELHEIRO MAIRINCK, Câmara Municipal. Conselheiro Mairinck-PR - $\mathbf{5 8}$ anos. 2019. Disponível em: <https://camaracmk.pr.gov.br/conselheiro-mairinck-pr--58-anos> acesso em: 18 jul. 2020.

CONSELHEIRO MAIRINCK, Prefeitura Municipal. Conselheiro Mairinck-PR. 2017. Disponível em: <http://www.conselheiromairinck.pr.gov.br/> acesso em: 18 mai. 2017.

CORDANI, Umberto G.; MARCOVITCH, Jacques; SALATI, Eneas. Avaliação das ações brasileiras após a Rio-92. Estudos Avançados, v. 11, n. 29, p. 399-408, 1997.

DE MOURA CARVALHO, Isabel Cristina. Educação ambiental: a formação do sujeito ecológico. Cortez Editora, 2017.

GUIMARÃES, Mauro; LAYRARGUES, Philippe Pomier. Identidades da educação ambiental brasileira. Brasília: Ministério do Meio Ambiente. Diretoria de Educação Ambiental, p. 25-34, 2004.

IBGE, Instituto Brasileiro de Geografia e Estatística. Censo Demográfico de 2010. Disponível em: <www.censo2010.ibge.gov.br>. Acesso em: 04 jul. 2017.

JACOBI, Pedro Roberto. Educação ambiental, cidadania e sustentabilidade. Cadernos de pesquisa, n. 118, p. 189-206, 2003.

JUNIOR, Enio Duarte Fernandez. Responsabilidade Civil Ambiental. Paco Editorial, 2015.

LAYRARGUES, Philippe Pomier. Conhecendo a educação ambiental brasileira. Brasília: Ministério do Meio Ambiente, p. 7-12, 2004.

LIMA, Gustavo Ferreira da Costa. Educação ambiental crítica: do socioambientalismo às sociedades sustentáveis. Educação e Pesquisa, v. 35, n. 1, p. 145-163, 2009.

NUNES, Ana Lúcia de Paula Ferreira; SILVA, Maria Batista da Cruz. A extensão universitária no ensino superior e na sociedade. Mal-Estar e Sociedade, Barbacena, Ano IV, n. 7, p. 119-133, jul./dez. 2011

REIGOTA, Marcos. O que é educação ambiental. Brasiliense, 2017.

SAUVÉ, Lucie. Educação Ambiental: possibilidades e limitações. Educação e pesquisa, v. 31, n. 2, p. 317-322, 2005.

UEPG, Universidade Estadual de Ponta Grossa. Operação Rondon 2017. UEPG, 2017. 